\title{
LOS GRANDES MAESTROS DE LA ADMINISTRACIÓN PÚBLICA: JUSTI, STEIN, BONNIN Y GONZÁLEZ
}

\author{
Omar Guerrero-Orozco \\ Universidad Nacional Autónoma de México, México \\ omarguerrer@yahoo.com
}

\begin{abstract}
RESUMEN
La administración pública, tal como otras disciplinas, tiene grandes pensadores cuyas contribuciones son las bases de su desarrollo científico. Son los líderes y maestros del campo de estudio. Durante el siglo XVIII, Johann Heinrich von Justi estudió la policía, siendo anterior a los primeros estudios en administración pública cuyos pioneros serían Lorenz von Stein (Alemania) y Charles-Jean Bonnin (Francia) un siglo más tarde. Stein desarrolló una versión administrativa del imperio de la ley en el siglo XIX. Por otro lado, inspirado por la Revolución Francesa y el Imperio de Napoleón, Bonnin creó el concepto moderno de la administración pública. Durante el mismo período, Florentino González, un destacado intelectual colombiano, escribió el primer libro sobre administración pública en una república. Este artículo estudia las contribuciones de estos grandes maestros de la administración pública.

Palabras clave: Administración Pública, Policía, Cameralismo, Historia intelectual de la administración pública.
\end{abstract}




\title{
THE GREAT MASTERS OF PUBLIC ADMINISTRATION: JUSTI, STEIN, BONNIN AND GONZÁLEZ
}

\begin{abstract}
Pubic administration, like other disciplines, has great thinkers whose contributions are the foundation of its scientific development. They are the leaders and masters of the field of study. During the 18th century, Johann Heinrich von Justi studied the "police", preceding the first studies in public administration that would be pioneered by Lorenz von Stein (Germany) and Charles-Jean Bonnin (France) one century later. Stein developed an administrative version of the rule of law in the 19th century. On the other hand, inspired by the French Revolution and Napoleon's Empire, Bonnin created the modern concept of public administration. During the same period, Florentino González, a notable Colombian intellectual, wrote the first book on public administration in a Republic. This article studies the contributions of these great masters of public administration.
\end{abstract}

Keywords: Public administration, Police, Cameralism, Intellectual history of public administration. 


\section{INTRODUCCIÓN}

Como en todas ciencias sociales, en la administración pública existen pensadores que sobrepasan a sus colegas por la eminencia de sus contribuciones. Su prominencia puede ser por encabezar una corriente de pensamiento, o por haber creado la disciplina que es el objeto de su estudio. También su elevado prestigio puede ser producto de ser el autor quien planteó un paradigma revolucionario por el cual se reconstruye una ciencia; o bien, los reconocimientos que tiene procedan de una actividad de recreación de un campo del saber hasta alcanzar planteamientos muy novedosos. Todos estos grandes pensadores son los líderes de una disciplina, son grandes maestros de la administración pública.

En la administración pública sobresalen Johann Heinrich von Justi (1717-1771), Lorenz von Stein (1815-1890), Charles-Jean Bonnin (17721846) y Florentino González (1805-1875), todos ellos por ser pioneros en su campo del saber. Justi destaca por ser quien en Alemania, durante el siglo XVIII, sistematizó el estudio de las ciencias camerales; y diferenciando y definiendo a la ciencia de la policía dentro de su conjunto. A mediados del siglo XIX Lorenz von Stein refunda la ancestral ciencia de policía bajo la forma alemana de ciencia de administración, centrando su desarrollo en las funciones sociales del Estado. En Francia la policía no alcanzó el rango de disciplina, sino más bien un desarrollo aplicado en estatutos, reglamentos y consejos para los funcionarios. De aquí que su contenido fue absorbido por la ciencia de administración pública, cuya conceptuación y desarrollo doctrinario emanaron principalmente de la revolución francesa. En 1808 Charles-Jean Bonnin formuló la primera definición con la voz administración pública. Bonnin funda este campo del saber tal y como lo cultivamos hoy en día. Sin embargo, la nueva disciplina no se había ensayado en un régimen republicano, labor y honor que tiene Florentino González, cuyo libro escrito en su natal Colombia en 1840 ostenta ese enorme merecimiento.

Los cuatro eminentes autores mencionados tienen el mérito de haber participado directamente en la creación y en el desarrollo inicial de la ciencia de administración pública. Este artículo tiene como propósito examinar la etapa original de la ciencia de administración pública, por medio de la cual tuvo lugar su sistematización conceptual y su difusión en Europa y América. 


\section{JOHANN HEINRICH VON JUSTI: LA CIENCIA DE POLICÍA}

La obra de Johann Heinrich von Justi sobre la ciencia de policía representa la etapa superior del cameralismo, que consistió en un movimiento surgido como una mera rutina practicada en las oficinas fiscales donde laboraban los empleados públicos en Alemania (Small 1909: 18). Posteriormente mudó en una cruzada de modernización de la administración pública, pues operó como racionalización del trabajo administrativo para alcanzar paralelamente la felicidad de los súbditos y el poderío del Estado. En suma: el cameralismo se convirtió en una técnica y una teoría de la administración de un tipo de Estado emergente, así como una manifestación del arte del gobierno cuya organización académica se fundó en el triángulo formado por la economía, la cameralística (finanzas) y la policía.

Durante muchos años el libro sobre policía de von Justi permaneció latente en las páginas de algunos escritos más recientes, hasta ser revalorada por Michel Foucault en la segunda mitad de la década de 1970 (Foucault 2004: 355-378). Este hecho significativo sucedió cuando Foucault impartió su curso anual en el Collège de France (1977-1978). La fuente de sus lecciones fue la versión francesa del libro de policía de Justi (Justi 1769); el cual, traducido al español por Antonio Francisco Puig y Gelabert, fue consultado por nosotros (Justi 1784). Desde entonces, algunos pensadores se han ocupado de revalorar y enaltecer el pensamiento de von Justi. Destaca Keith Tribe, quien se ocupa de la policía y del papel eminente de von Justi, principalmente con referencia a la primera como técnica de gobierno y herramienta de la circulación mercantil (Tribe 1995: 18-22). Con respecto al tema económico se debe mencionar de manera relevante a Jürgen Georg Bacckhaus, que declara sin reserva alguna que von Justi es el fundador universal de la economía política a través de sus lecciones en la Academia Teresiana de Viena, dictadas en 1750 (Backhaus 2009: VI-VII). Asimismo, Ulrich Adam atribuye a von Justi ser uno de los fundadores de la economía, pero principalmente quien "perfeccionó" al cameralismo (Adam 2005: 11). Este último agrupa a la triada mencionada de ciencias en cuyo centro reina la policía, la cual, según Adam, es hechura de la política económica.

\section{ORIGEN DE LA CIENCIA DE POLICÍA}

Con von Justi, el cameralismo alcanza su etapa suprema porque él entiende los conceptos como categorías científicas. Pero en su pensamiento destaca el estudio la policía, que antes del siglo XVIII no se había entendido adecuadamente al permanecer incógnita dentro de un mundo gubernamental indiviso; era todavía un suceso anónimo e indiferenciado dentro otros fenómenos estatales. La identificación y definición de la 
policía dentro de los negocios públicos consistió en el desarrollo de un conocimiento singular, que dejó de estar confundido o subordinado a materias como la política, la hacienda y la cameralística. Paralelamente, la expresión policía surgió de la necesidad de una mayor gobernabilidad a través de una nueva administración, cuyos funcionarios obtendrían mayor profesionalización. Esto mismo impulsó una formación propiamente administrativa del alto servicio público en los asuntos interiores, diplomacia, finanzas y economía, así como la preparación del funcionario público en la retórica y la hermenéutica. Von Justi creó una ciencia fundada en principios generales, y se establecieron las bases y las categorías para el desarrollo de la policía.

Von Justi partió del imperativo científico de diferenciar la policía y otras disciplinas, porque juzgó que no existe regla general que no tenga excepción, sea entre ciencias emparentadas, sea una disciplina que se aborde separadamente. En todo caso, es útil para el progreso de todas las ciencias que se fijen sus límites con claridad, porque no se conoce una disciplina sino de manera imperfecta cuando se obvían todas sus partes y se pasan por alto temas útiles cuando se tratan muchas ciencias al mismo tiempo (Justi 1784: XI, XIII-XIV). He aquí el principio de generalización de un hecho social del que no se puede prescindir tratándose de su validez universal, toda vez que en lo tocante a las disciplinas singulares Justi asegura que es menester no olvidar que "cada una de ellas tiene su alcance y sus límites".

Ha nacido la ciencia de la policía.

\section{LA POLICÍA PRODUCE PODER}

Como lo adelantamos, von Justi distinguió a la policía, por un lado, y a la política (en alemán, Staaskunst, arte del Estado) por el otro. En este punto, Foucault explica que, a través de esta distinción, la política asume una tarea fundamentalmente negativa: defender al Estado de sus enemigos; en tanto que la policía se atribuye la función positiva de nutrir por igual la vida de los ciudadanos y la fuerza del Estado. Pero, como la policía entrańa una dualidad funcional: expandir las fuerzas del Estado y estimular la prosperidad de la sociedad, la policía es lo que capacita al Estado para incrementar su poder y ejercer su fuerza al máximo. Por otra parte, la policía tiene que mantener felices a los ciudadanos, entendida la felicidad como supervivencia, vida y vivir mejor (Foucault 1982: IX). El mérito de Foucault radica en identificar lo que considera ser el propósito del arte moderno del gobierno: la racionalidad estatal, que consiste precisamente en que el desarrollo de los elementos constitutivos de la vida de los individuos, nutra al mismo tiempo el desenvolvimiento del poder del Estado. 
El concepto poder se aparta de las categorías politológicas que lo identifican con el dominio y la jerarquía. Von Justi afirma que el poder de un Estado consiste en los bienes muebles de los súbditos que lo integran, y que son el producto del trabajo de los hombres (Justi 1784: 4). Como el poder estatal radica en la propiedad de la ciudadanía, el Estado es más poderoso en función de la prosperidad de sus habitantes. Convertida antaño casi en una necromancia -una doctrina dominada por el misterio-, la policía resurge en la actualidad para patentizar que el modo como antańo se regía es la forma como hoy se gobierna o se debe gobernar. En efecto, policía significa el orden y la disciplina que reinan entre los ciudadanos que integran a la república. En tiempos remotos los griegos y romanos la entendieron como la sabiduría concerniente al orden, las comodidades y la hermosura, que son las bases de las repúblicas (Justi 1784: XVII). Von Justi discierne que en su tiempo esa palabra tenía dos sentidos diferentes, uno amplio, el otro estricto. En primero comprende bajo el nombre policía las leyes y reglamentos que conciernen al interior del Estado, que se orientan a afirmar y a aumentar su poder, hacer un buen uso de sus fuerzas y procurar la felicidad de los súbditos. En una palabra, ella se refiere al desarrollo del comercio, la hacienda, la agricultura, las minas, las maderas y los bosques; entendiendo que la felicidad del Estado depende de la inteligencia con que todas estas cosas son administradas. La palabra policía, en el segundo sentido, se refiere a todo lo que contribuye a la felicidad de los ciudadanos, y principalmente a la conservación del orden y la disciplina. Comprende, pues, los reglamentos que miran a hacerles la vida más cómoda y procurarles las cosas que necesitan para subsistir" (Justi 1784: 1-2).

Las ideas precedentes han brotado de manos de uno de los más grandes teóricos del Estado, que lo entiende como una institución perfectible, lo mismo que propensa a su degeneración. De modo que, para lograr lo primero y evitar los peligros de lo segundo, deben ser conocidas las fuerzas y las debilidades del Estado. Una vez que son sabidos los defectos del Estado y estimado sus potencias, éstas puedan incrementarse de un modo tal que crezcan más que las de los Estados vecinos, toda vez que al mismo tempo produzcan repercusiones positivas para sus propios habitantes. La policía consiste en un logos, en un saber de cuyo trabajo intelectual brota la explicación de las condiciones objetivas de la existencia del Estado, de sus precariedades y sus facultades.

La policía es entendida como una ciencia aplicada al mejoramiento del Estado, por la vía del adelanto de las condiciones de existencia de la sociedad. Ella estudia los campos de actividad del Estado, y consiste en el conocimiento que discierne el qué del gobierno con base en principios y máximas del Estado; trata asimismo con el cómo del gobierno, pues explica 
el modo en que opera para fortalecer al Estado y hacerlo más poderoso.

La ciencia de la policía no pereció cuando pasaron sus días de gloria. Siguió cultivándose casi hasta mediados del siglo XIX, sobre todo debido a las sucesivas reediciones de los libros sobre su materia, o bien por las traducciones a otros idiomas. Por ejemplo, el tratado sobre policía, comercio y finanzas de Joseph Sonnenfels (1832) - publicado originalmente en 17651767- tuvo una octava edición en 1819, y fue traducido al italiano en 1832. Sin embargo, su más grande cultivador en ese entonces fue Robert von Mohl (1799-1875), cuya traducción italiana de su libro propició una divulgación más extendida de la policía (Mohl 1891).

Sin embargo, el destino final de la policía en Alemania llegó a su punto de culminación con el establecimiento del Estado de derecho, donde gradualmente dejó de tener un sitio, y finalmente fue reemplazada por la administración pública. La inmensa obra de von Mohl sobre esta materia fue la tumba honrosa de la policía, la cual, sin embargo, dejó su huella imperecedera en la nueva disciplina y ciertamente todavía late con alguna animación en las funciones sociales del Estado

\section{LORENZ VON STEIN: LA TEORÍA DE ADMINISTRACIÓN PÚBLICA}

En los escritos de Lorenz von Stein llega a su último tramo vital la ciencia de la policía, y es reemplazada la ciencia de administración pública.

\section{DE LA POLICÍA A LA ADMINISTRACIÓN PÚBLICA}

Stein se propuso crear un concepto de administración tomando distancia de la policía, a la cual considera como una disciplina del pasado. Para alcanzar su propósito, él explica que para la teoría de la administración es muy importante definir claramente el concepto policía, merced a la incertidumbre y oscuridad que le rodea. Sin embargo, como suficiente una definición puramente formal, más bien es necesario que su idea sea expuesta históricamente, tal y como surgió. Porque en el siglo XVIII la policía significaba el conjunto de las formas mediante las cuales se realizaba la intervención del gobierno mediante la administración pública.

Evocando el pensamiento de von Justi, Stein apunta que la policía surgió con el nacimiento mismo del gobierno y ella se entendía como el arte del Estado que, en contraste con la política, abarcaba todas las actividades del propio Estado. En el siglo XVII la policía se comienza a sistematizar alrededor del derecho natural, como un principio que se extiende al conjunto de todas las tareas de un gobierno, y que se sintetiza 
en el eudemonismo. Este mismo principio es, asimismo, el origen de la postrera escisión del concepto de policía, cuando se distingue la policía del bienestar y policía de la seguridad. Con el paso del tiempo la policía del bienestar fue evolucionando bajo la forma de administración interna, como un espacio autónomo separado de las finanzas y la economía. Al final del proceso, la policía se desvanece y ocupa su lugar la administración interna propiamente dicha (Stein 1897: 121-122). En el siglo XVIII, la policía adquirió un significado diferente porque se convirtió en una relación singular entre gobierno y administración. La índole del derecho público en ese siglo radicaba en la fusión de la legislación y la administración, suceso que explica lo que Stein califica como omnipotencia del Estado. Pero en el siglo XIX ambas se separaron porque en ese entonces entró en escena un principio que por el cual, la ley ordena todas las actividades del poder del Estado. De aquí que el gobierno ya no es mera policía, toda vez que ésta se convierte en una parte, en una función y en un derecho del gobierno.

Stein, quien identificó con precisión el concepto de policía como inherente a todas las actividades del Estado, paradójicamente desarrolla una idea de administración pública muy similar. Adolfo Posada hizo notar que "para Stein, en definitiva, todo lo que hace el Estado es administrar", y que llevado por el amor a su especialidad dio a la administración como ciencia tal amplitud que la situó como el núcleo de las ciencias del Estado (Posada 1892: 37, 41-43). Este hecho explica por qué en Alemania no se creó una nueva ciencia, sino que se transformó la que se había establecido más de un siglo antes. La policía fue reemplazada por la administración pública, pero su desvanecimiento no fue de un solo golpe, ni tampoco de súbito. Todavía hallamos su rastro hacia el final del siglo XIX en un libro de Franz von Holtzendorff, quien concibe a la policía como una disciplina que comprende los principios mediante los cuales se asegura la prosperidad de la sociedad y se previenen los daños que la amenazan (Holtzendorff 1888: 5-6). Pero Holtzendorff no invoca el pensamiento de Lorenz von Stein, sino las ideas de Robert von Mohl, quien definió a la policía como la ciencia de la organización y dirección racional del Estado en sus relaciones interiores (Mohl 1841: 152-153). No todos los autores cultivaban en ese entonces a la ciencia de la administración, prefiriendo todavía el estudio de aquella otra que la precedió.

\section{REFundaCión DE La CIENCIA DE ADMINISTRACIÓN EN AlEMANIA}

Stein se ocupó con profundidad de la policía con el objeto de recrear una nueva disciplina, a partir de su profunda transformación. Y de tal modo lo hace saber, cuando afirmó que con la publicación de su libro sobre de teoría de administración pública ofrecía al público su esfuerzo por elevar la doctrina de la administración a la condición de ciencia sistemática (Stein 
1897: 7). Von Stein es autor de un libro enorme que tituló Teoría de la Administración (Die Verwaltungslehre), pero que, siendo es tan voluminoso en sus diez tomos, lo consideró inapropiado para el estudio general de esa teoría (Stein 1865-1884). Este escrito, al que el propio Stein consideró como "obra mayor", debió a ser acompañado por libro sintético apto para la enseńanza de la disciplina, un texto más digerible que Stein tituló Manual de Teoría de la Administración (Handbuch der Verwaltungslehre), y fue publicado en 1871. En suma, a través de este libro Stein se propuso demostrar que las materias prácticas de la administración pública son dignas de recibir un tratamiento científico superior.

El esfuerzo de Stein ha sido enaltecido por pensadores administrativos que le confieren la paternidad universal de la nueva disciplina, como Manuel García Pelayo, quien se la otorga junto con Robert von Mohl, pues cree que con la labor de ambos pensadores fueron reemplazadas las ciencias camerales (García Pelayo 1949: 48). A pesar de que la posición de García Pelayo tiene fundamentos sólidos, más bien debemos entender que la cruzada científica de Stein se refiere al caso alemán donde la ciencia de la policía será refundada por él mismo como ciencia de administración. En la edición italiana de su libro, Stein explica que los quehaceres insignes de la administración pública la elevaron al pedestal superior en el seno de las ciencias del Estado, porque tiene como deber la perfección de los individuos donde se tiene conciencia sólo del Estado, más que de organizaciones político-sociales inferiores (Stein 1897: 17, 37). Este concepto tuvo una gran influencia en Italia, donde Augusto Barbieri definió a la ciencia de administración como el estudio del modo como el Estado ejercita su acción sobre la sociedad, y cuál es esa acción cuyo propósito es su desarrollo económico, físico e intelectual (Barbieri 1888: 22).

\section{El SISTEMA DE LA CIENCIA POLÍTICA POSITIVA}

En la edición italiana de 1897 Stein apunta que la acción administrativa del Estado es el campo más vasto del examen de un conjunto de conocimientos, que él denomina sistema de ciencia política positiva. El sistema está formado por el estudio del ejército, las relaciones internacionales, las finanzas, la administración de justicia y la administración interna. Todas ellas, sin embargo, son ciencias independientes que confluyen en el sistema porque tienen la finalidad común de facilitar el libre y perfecto desarrollo del individuo, junto con la administración interna. Por su parte, esta última estudia el modo y los medios con los cuales el Estado actúa en provecho de los intereses comunitarios, y que a su vez comprende a la estadística, la policía y la alta superintendencia. La ciencia de administración pública, que comprende toda la actividad del Estado, atiende principalmente la relación de esta actividad con la sociedad por cuanto promueve sus 
intereses. Comprende, pues, el conjunto de conocimientos contenidos en la economía política, la hacienda pública, la política y la administración de justicia. Todas ellas constituyen la esfera de las ciencias del Estado consideradas desde el ángulo de la actividad, pues Stein asume que todas ellas "son administración".

Von Stein establece como objeto de la administración pública la vida del Estado en el hecho, esto es, actuando, así como la comprensión del tema social como problema de la administración misma, desde el punto de vista del Estado. Él infiere, bajo la presión de la creciente omnipotencia del Estado, una gestión de los intereses sociales por medio de la administración pública.

Pocas exposiciones científicas desarrollan una idea administrativa de un modo tan pleno. Sin dejar de lado el entramado complejo de las categorías y de sus relaciones dentro del discurso de Stein, no se puede obviar que en sus escritos se palpa la trascendencia de la administración pública visualizada como un factor relevante para comprender los alcances de la vida social, así como el destino de los individuos. Asimismo, la administración pública social queda explicada con toda claridad, pues en todo caso los deberes sociales inherentes a las funciones estatales obedecen a la idea de la constitución como el espacio de la ciudadanía y de la libertad, en tanto que la administración pública tiene la elevada vocación de hacerlos realidad. Con Lorenz von Stein la ciencia de la administración consolida su merecido lugar en el conjunto de las social ciencias.

\section{CHARLES-JEAN BONNIN: LA CIENCIA DE ADMINISTRACIÓN PÚBLICA}

En Francia, la policía tuvo un tratamiento diverso al que se le dio en Alemania por motivo directo de la Revolución. En ese país la policía fue restringida a la seguridad pública. Como lo explica Charles-Jean Bonnin, en tanto la administración es la parte del gobierno destinada a poner en armonía las personas y las cosas, la policía "es el ojo de vigilancia" que previene que esa armonía se pueda turbar. La administración es la dirección de las personas en sus relaciones sociales, mientras la policía es la vigilancia de las acciones que las pueden perjudicar. En efecto, "la administración dirige y la policía reprime: estos son los dos medios de que se vale la acción administrativa, principal el uno y accesorio el otro" (Bonnin 1829, 48-49).

Mucho tiempo antes de que en Alemania la policía fuera estrechada a la seguridad pública, y la administración comenzada a desarrollar por Stein como la ciencia que la reemplazó, en Francia Bonnin sentaba las bases universales de la misma. 
Bonnin había desaparecido del mapa intelectual de la administración pública por más de un siglo, cuando Pierre Escoubé lo descubrió y rescató del silencio. Sus primeras líneas fueron para decir "que el nombre de Bonnin está, actualmente, totalmente olvidado" (Escoubé 1958: 15-18). Hoy en día los franceses han vuelto a rendirle el tributo que merece: el pensador franco-polaco Georges Langrod dijo con toda razón "que la ciencia de administración, en el sentido moderno de esta expresión, nace en Francia con el siglo XIX. Su pionero es Charles-Jean Bonnin, autor de los Principes d'Administración Publique, cuya primera edición se remonta a 1808" (Langrod 1961: 7). Igualmente, Jacques Chevallier y Dániele Loschak comentaron que Bonnin "puede ser considerado como el verdadero fundador de la ciencia administrativa francesa" (Chevallier y Loschak 1978 I: 23).

\section{DEFINICIÓN DE ADMINISTRACIÓN PÚBLICA}

Incluso la definición de administración pública emana de una nueva fuente: la sociedad. Bonnin fue uno de los primeros pensadores en observar a la sociedad como algo emergente en la modernidad, cuyos integrantes habitan un ancho mundo de publicidad donde sus relaciones se multiplican acrecentando su interdependencia. La sociedad entraña propiamente los asuntos públicos, es decir, materias de la sociedad como conjunto, así como la manera en que ellos se conducen. Pero la dirección de los negocios públicos tiene tal grado de complejidad que requiere dos tipos de dirección diferentes, para atender las necesidades del Estado. Un primer tipo refiere un conjunto de administraciones especiales que dirigen ramas especializadas, como son los impuestos o los bosques. El otro tipo, que es el principal porque constituye una definición primigenia, tiene un carácter general y propiamente se trata de "la administración pública, es decir, la que tiene la dirección de los asuntos comunes respecto del ciudadano como miembro del Estado" (Bonnin 1808: 5).

Este concepto sistemático es la primera definición de la administración pública, tal como brota de los procesos políticos de la Revolución y que maduraron en el Imperio con Napoleón. La administración pública tiene a su cargo la dirección de los asuntos comunes del ciudadano en lo que atañe a su persona, así como sus bienes y sus acciones por cuanto miembro del Estado. Pero también se interesa por su persona individual, sus bienes y sus acciones por cuanto incumben al orden público (Bonnin 1809: 59). Hay en efecto negocios comunes entre los miembros del Estado de los cuales brota una gestión igualmente común, pues no obstante que esos miembros son individuos, su persona, sus acciones y sus bienes como conjunto, son de público interés. La administración por cuanto pública emana de esa comunidad como dirección de los intereses compartidos de 
todos sus miembros. El carácter inherente de la administración es actuar, obrar sin cesar, pues su acción es en todos los momentos por ser interesante al orden público (Bonnin 1808: 4). Su relación con los administrados es de todos los días, en todo instante, y comprende su resguardo individual y común, así como la prosperidad pública, los impuestos, el servicio militar, la agricultura, la industria, el comercio, las obras públicas, las prisiones, los hospitales, la salubridad y la salud. Estas tareas, propias del quehacer del administrador público, son sus deberes más importantes como hombre de Estado.

\section{OBJETO DE LA CIENCIA DE ADMINISTRACIÓN PÚBLICA}

Una vez definida la administración pública, Bonnin se aboca a delinear sus principios como disciplina científica. Cuánta razón le asiste cuando afirma que la ciencia de administración pública es nueva, pues ella ha emanado directamente de los progresos de la razón en materia legislativa y de organización política dentro de los temas modernos. Bonnin, refrendando la excepcionalidad de su época, proclama que "ha llegado el momento de crear la ciencia de administración” porque los espíritus están más abiertos a apreciar sus ventajas y beneficios (Bonnin 1808: 68). Por consiguiente, la ciencia de administración aspira a trascender en el tiempo y el espacio, y establecer principios universales, pues los nuevos tiempos tienden a derramarse por toda Europa y América donde la Revolución francesa tenía adeptos. Ante hechos tan móviles y mutantes, los principios de la administración pública deben ser fijados, estar apoyados en leyes positivas, y ser sumisos a una marcha uniforme e invariable (Bonnin 1812 I: XII). La nueva ciencia surge como una necesidad social y su existencia tiene como propósito ocupar un espacio público emergente, donde la sociedad como un todo se vincula con las partes individuales que la integran.

La ciencia de administración ocupa un terreno de extensa publicidad emergente de la actividad ciudadana, donde el destino individual no se puede cultivar sin el aseguramiento del destino de la comunidad, y donde el designio social está penetrado por la fuerza de la personalidad individual. Es el conocimiento que trata de un complejo cúmulo de vínculos entre la sociedad y los administrados, que se aplica a la conservación de esas relaciones por medio del obrar de la autoridad pública sobre los hombres y las cosas que pertenecen a los propios hombres, pero siempre en función del interés de todos. Como saber científico caracterizado como teoría y como práctica social, puede entonces considerase como el conocimiento de ciertas relaciones sociales inherentemente administrativas. 
La administración pública así concebida entraña una acción social que sustenta una ciencia basada en elementos naturales y brinda los fundamentos a los "principios universales y fijos". El concepto de administración, amplio y comprensivo, tiene una correspondencia igualmente magna: la ciencia de la administración que

[...] es, en efecto, la ciencia de las relaciones entre la comunidad y los individuos, y de los medios de conservación de esas mismas relaciones por la acción de las leyes y los magistrados sobre las personas y las propiedades, en todo lo que interesa el orden social (Bonnin 1829: 3-4).

Es una disciplina social porque toma como base a la sociedad y hace descansar su espíritu en la colectividad humana. La ciencia administrativa debe ser considerada como el conocimiento de los principios de las relaciones sociales, es decir, el análisis de las propiedades y fenómenos de estas relaciones, así como su aplicación a las personas y las cosas de las reglas que conjugan dichas relaciones con el interés común.

Bonnin edificó las bases de la ciencia de administración pública a través del examen de las proposiciones disciplinarias que le son inherentes, pues juzgando que todas las ciencias descansan en principios fundamentales que las ordenan y clasifican, la administración también reposa en principios que le son propios. Él se propuso tratar de la administración como ciencia con respecto a la teoría que sustenta los principios productores de las cosas administrativas; como arte por cuanto la aplicación de los principios a la ejecución de las leyes, y como institución política con respecto al conjunto de la organización de las autoridades ejecutoras (Bonnin 1829: 14). Fue de tal modo como formuló su sistema completo de la ciencia administrativa, sobre la cual establece los cuatro principios de la administración pública:

- Que la administración nació con la asociación o comunidad.

- Que la conservación de ésta es el principio de la administración.

- Que la administración es el gobierno de la comunidad.

- Que la acción social es su carácter, y su atribución la ejecución de leyes de interés general.

Tales son los principios de la administración pública, cuyo rango de conocimiento es universal porque cualesquiera que sean los sistemas de administración de los diversos pueblos con relación a las personas y las cosas, la doctrina administrativa es independiente de los tiempos y los países, y es por consecuencia universal. Bonnin formuló una profecía que 
se realizó plenamente: "llegará un día en el que se demostrará esta verdad y se disminuirá todo el mérito de mi obra, pero yo habré indicado la senda que otros podrán rectificar y embellecer" (Bonnin 1829: XXIV).

\section{FLORENTINO GONZÁLEZ: UNSISTEMADEADMINISTRACIÓN PARA UNA REPÚBLICA}

Bonnin mencionó que en América, la Revolución tenía adeptos. Uno de ellos, latinoamericano, fue Florentino González, un pensador administrativo muy destacado. Nacido en Colombia, es autor del primer tratado de administración pública escrito en idioma español, toda vez que es asimismo el primero donde esa administración se estudia en un régimen republicano. González se había propuesto trabajar un texto relativo a una administración descentralizada y, a pesar de su devoción doctrinaria por Bonnin, no pudo conciliar con un sistema de administración pública preparado para un régimen imperial centralizado. Sin embargo, uno de los méritos más relevante de Florentino González fue introducir la ciencia de administración pública en América, precisamente, a través de Bonnin.

\section{EL ESTUDIO DE ADMINISTRACIÓN PÚBLICA}

González pugnó por la descentralización de la vida local porque presentía los males de la centralización, a la cual identificaba con el despotismo. Para dar pauta al sistema de administración pública republicano, ante todo se propuso sentar las bases epistemológicas de su estudio; explicando que "la ciencia administrativa es el conocimiento de los principios, en virtud de los cuales debe arreglarse la acción de las autoridades a quienes se encargue la dirección de los intereses y negocios sociales, que tengan el carácter de públicos" (González 1840). La nueva disciplina está encaminada a ofrecer el conocimiento de los principios que rigen a los asuntos de orden público, que destacan principalmente por su índole social. Estos principios, sustentados en el saber científico, son la guía que sirve de brújula a la actividad de las autoridades para hacer realidad el destino y misión de la administración pública; es decir, conservar las relaciones entre la sociedad como un todo, con las personas individuales que la integran.

Florentino González explica que los intereses sociales son inherentes a la condición del individuo como miembro de la sociedad, y por lo tanto, a la sociedad en sí, que contrastan con aquellos otros de tipo privado que se refieren a los que el individuo cuida por motivos de su propia utilidad. Así, con diferencia de los intereses privados como el ejercicio del pensamiento y de la industria, o la profesión de un culto religioso, los intereses sociales se refieren a la población, el usufructo de los productos naturales, la seguridad de los habitantes, la educación pública, el matrimonio, los decesos y las 
contribuciones, que por naturaleza tienen un carácter público.

Una vez que González identificó a los intereses sociales, explica que "la administración pública es la acción de las autoridades sobre los intereses y negocios sociales, que tengan el carácter público, ejercida conforme a las reglas que se hayan establecido para dirigirlos" (González 1840 I: 1). La idea acerca de la administración pública como acción, González la extiende a los funcionarios públicos. De manera que lo que él aquilata como una buena administración consiste en los resultados ventajosos que se obtienen, así como en los funcionarios que la ejercitan. La buena administración debe hallarse en el nivel nacional y en el ámbito municipal, al primero de los cuales entiende la acción de la autoridad pública sobre los intereses y negocios sociales relativos a la nación; en tanto que el segundo es la acción de la autoridad pública sobre los intereses y negocios referentes a las secciones de la nación.

Una vez formulado su esquema de la ciencia de administración, Florentino González procede a examinar la administración pública como objeto de esta ciencia.

\section{LA ADMINISTRACIÓN PÚBLICA EN MOVIMIENTO}

Un gran acierto de los científicos de la administración del siglo XIX fue el estar conscientes de la imposibilidad del orden jurídico, sin el concurso de la administración pública, concebida como la actividad cuya mira es el beneficio del interés social. González asegura que en vano se darían las mejores disposiciones para un pueblo, si no se facilitan los medios con los cuales se pudiera poner en práctica. El beneficio no llega a la sociedad cuando las reglas permanecen en el papel, porque no sólo interesa cuidar que las leyes sean buenas, sino también que se puedan aplicar. Precisamente la ejecución es la esencia de la administración pública, y por extensión, "esta última parte, es decir, la parte adjetiva, es la que toca a la ciencia administrativa” (González 1840 I: 16).

A la ciencia de administración concierne la ejecución de la ley y, por lo tanto, ante el carácter sustantivo que representa el derecho, su aplicación es la parte adjetiva en la que descansa la naturaleza de la administración pública como acción. Lo que en Europa se conocía como acción administrativa, González la denomina movimiento administrativo. Este movimiento consiste en el proceso por el cual la acción administrativa desciende desde el jefe del Estado, hasta los funcionarios que laboran de cara a la ciudadanía, y de tal modo recorre de arriba a abajo a la escala administrativa (González 1840 I: 39). El movimiento administrativo está caracterizado por un proceso de acción y reacción, cuyo estímulo primario 
parte del cuidado que el jefe de Estado tiene para que sus colaboradores se desempeńen con acierto, usando al efecto una suave, pero estricta vigilancia, y que recuerde los deberes a los servidores públicos, aclare sus dudas y produzca informes sobre sus labores como un efecto de reacción.

Como el movimiento administrativo no es un fin en sí mismo, debemos recordar que toca a la administración pública personificar el aspecto adjetivo de la ley. González explica que "el movimiento social, el progreso de la nación y las variaciones que naturalmente producirán estas causas en los intereses, exigen también un movimiento administrativo rápido, activo y eficaz" (González 1840 I: 40). Es la existencia del movimiento administrativo, por la movilización de recursos públicos que entraña, lo que explica por qué en los países donde existe la buena administración hay prosperidad, bienestar y grandes obras públicas de interés social. La fuerza y la riqueza de la sociedad han llevado a la cima lo que los individuos sólo podrían aspirar como proyecto. El movimiento administrativo devela el sentido de la buena administración, como aquélla que establece tres reglas: el mejor medio de acertar; la facilidad para exigir responsabilidad moral y legal; y la facilidad de ejecución.

Inherentes al movimiento administrativo son los medios que facilitan el desempeño de la administración pública. González los clasifica en dos categorías: medios pasivos y medios activos. El territorio debidamente dividido constituye el medio pasivo esencial de la administración pública, porque es el espacio físico que comunica la autoridad pública y los intereses sociales que manejará, y a los que facilita su movimiento. Una adecuada administración territorial basada en la organización de provincias, cantones y distritos parroquiales, como en Nueva Granada (Colombia), favorece que el ejercicio administrativo se realice de manera uniforme, sistemática y oportuna. Este esquema territorial es el elemento básico de su teoría municipal, pues es el distrito parroquial donde las familias están en contacto directo entre sí; allí es donde se palpa la sociedad, donde se ve lo que ella es y donde el hombre conoce la ventaja de estar reunido con sus semejantes. Es allí donde siente el poder y la fuerza de lo que carece el individuo aislado, y donde experimenta los bienes o los males de la administración (González 1840 I: 18). Lúcidamente explica que las ideas de nación, de provincia y de cantón, tienen algo de aéreo, en tanto que el distrito parroquial es "realidad, todo se toca, se ve y se palpa". El territorio debidamente dividido, se complementa con otros dos medios pasivos de la administración pública: la carta geográfica y la estadística.

Florentino González fue olvidado durante muchos años, incluso en su natal Colombia, principalmente porque su libro se dejó de publicar. Más bien su texto tuvo una segunda edición en Ecuador cuando corría el año 
de 1847, y que parece no tuvo mucha difusión (González 1847). Hasta donde sabemos González permaneció inadvertido el resto del siglo XIX y en buena parte del XX, hasta que su libro fue nuevamente publicado en 1994 en su país de origen (González 1994). Desde entonces, su tratado es lectura obligada y reconocida entre un público cada día más extenso

\section{EPÍLOGO}

El ideario administrativo desarrollado por von Justi y von Stein, que dio vida y fortificó a la ciencia de administración en Alemania, tuvo una intensa repercusión en Italia, España y los Estados Unidos. Bonnin fue muy influyente en Francia, España, Portugal y América latina. Ambas raíces intelectuales están bien definidas entre sí, pero no sólo tienen muchos temas en común, sino son los más importantes. Destaca el énfasis en el Estado de derecho, las funciones sociales y el bienestar público. En Alemania se desarrolló el concepto administración interna para destacar los deberes sociales del Estado, en tanto que en Francia se acuñó el término moral de la administración.

En buena medida sus respectivos cuerpos de conocimiento constituyen un solo orden epistemológico, merced a mutuos intercambios primigenios. Uno de ellos muy relevante es la voz policía (Dorwart 1971: 14-15), que pasó de Francia a Alemania en la época de Carlos V (1519-1558). En Italia, donde Stein fue la figura predominante, el libro de Bonnin fue publicado muchos años antes del arribo de las ideas del distinguido profesor alemán (Bonnin 1824). Ese escrito no pasó desapercibido en Italia, como es notorio en un texto de Pascuale Liberatore, quien cita a Bonnin (Liberatore 1836: 179). Bonnin asimismo antecedió a Stein en España, donde su texto también fue editado y tuvo una amplia difusión (Bonnin 1834). Florentino González, a partir de la edición de 1994, es muy consultado en toda la América latina, así como en España. Un libro publicado en 1922 deja ver en sus páginas gran similitud con el texto de González, lo que hace presumir su influencia sobre José Venegas, su autor (Venegas 1922).

El hecho significativo del encuentro de pensadores no sólo eminentes, sino participantes directos del nacimiento de la ciencia de administración pública, los puso en contacto ante el mismo público lector y de tal modo el cultivo de la nueva disciplina generó su desarrollo doctrinal hacia el presente. Dos raíces conceptuales emparentadas creciendo muy próximas entre sí, y un sólo cuerpo epistemológico. Esta es la ciencia de administración pública. 


\section{REFERENCIAS}

Adam, U. (2005). The Political Economy of J.H.G. Justi. Oxford: Peter Lang.

Backhaus, J. (2009). Introduction. En Backhaus, J. (Ed.), The Beginning of Political Economy: Johann Heinrich Gottlob von Justi. Nueva York: Springer.

Barbieri, A. (1888). Elementi di Scienza dell'Amministrazione. Bologna: Nocola Zanichelli.

Bonnin C. (1808). De l'Importance et de la Nécessité d'un Code Administratif. París: Garnery, Libraire.

. (1809). Principes d'Administration Publique, por servir a l'Études des Lois Administratives, et Considérations sur l'Importance et la Nécessité d'un Code Administratif, Suvies du Project de ce Code. París: Clement Fréres Libraires.

(1812), Principes d'Administration Publique. París: Renaudiere Imprimeur-Libraire, dos tomos.

. (1824). Principii di Amministrazione Pubblica. Nápoles: Nella Stamperia Francese.

- (1829). Abrégé des Principes d'Administration. París: Amable Costes Libraire-Editeur.

. (1834). Compendio de los Principios de Administración. Madrid: Imprenta de don José Palacios.

Chevallier, J. y Loschak, D. (1978). Science Administrative. París: Libraire Générale de Droit et Jurisprudence, dos tomos.

Escoubé, P. (1958). Charles Jean Bonnin, Précurseur de la Science Administrative. La Revue Administrative, 11, 15-18.

Foucault, M. (1982). Dioses, Pastores y Hombres. El Origen de la Tecnología del Poder y la Razón de Estado. Revista jSiempre!, VI, I-IX.

Seuil. . (2004). Securité, Territoire, Population. París: Gallimard 
Holtzendorff, F. (1888). Principios de Politica. Madrid: Librería de Fernando Fe.

García Pelayo, M. (1949). La Teoría de la Sociedad en Lorenz von Stein. Revista de Estudios Politicos, 47, 43-90.

González, F. (1840). Elementos de Ciencia Administrativa. Bogotá: Imprenta de J.A. Cualla, dos tomos.

(1847). Elementos de Ciencia Administrativa. Quito: Imprenta de J.A. Cualla.

(1994). Elementos de Ciencia Administrativa. Bogotá: Escuela Superior de administración Pública.

Justi, J. (1769). Elements Gènèraux de Police. París: Rozet Libraire.

(1784). Elementos Generales de Policía. Barcelona: Impresora del Rey nuestro Señor.

Langrod, G. (1961). La Science de l'Administration Publique en France au 19éme et au 20éme Siecle: Apercú Historique et État Actual. La Revue Administrative, 79, 5-11

Liberatore, P. (1836). Della Amministrazione Pubblica. Nápoles: Tipografia della Sirene.

Mohl, R. (1891). La Scienza dell'Amministrazione Secondo i Principii de lo Stato Legale. Turín: Stamperia dell'Unionne Tipografico-Editrice, volumen primero.

. (1987). El Concepto de Policía y el Estado de Derecho. En VV.AA, Liberalismo Alemán en el Siglo XIX. Madrid: Centro de Estudios Constitucionales, 1987.

Posada, A. (1892), Introducción y Exposición de la Organización Administrativa en España. En Mayer, J., La Administración y la Organización Administrativa en Inglaterra, Francia, Alemania y Austria. Madrid: España Moderna.

Tribe, K. (1995). Strategies of Economic Order: German Economic Discourse: 1750-1950. Cambridge: Cambridge University Press. 
Small, A. (1909). The Cameralists: The Pioneers of German Social Policy. Chicago: The University of Chicago Press.

Stein, L. (1897). La Scienza della Pubblica Amministrazione. Turín: Unione Tipografico-Editrice.

Sonnenfels, J. (1832). Scienza del Buon Governo. Milán: Giovanni Silvestri.

Vanegas, J. (1922). Elementos de Administración Pública. Bogotá: Casa Editorial de la Cruzada.

Recibido: 05-03-2015

Aceptación de la versión final: 29-05-2015 